\title{
Examining Mediators of the Relationship Between Community Mobilization and HIV Incidence Among Young South African Women Participating in the HPTN 068 Study Cohort
}

\author{
Anna M. Leddy ${ }^{1}$ (D) $\cdot$ Torsten B. Neilands $^{1} \cdot$ Rhian Twine $^{2} \cdot$ Kathleen Kahn $^{2,3} \cdot$ Jennifer Ahern ${ }^{4} \cdot$ Audrey Pettifor $^{2,5}$. \\ Sheri A. Lippman ${ }^{1,2}$
}

Accepted: 7 October 2021 / Published online: 19 October 2021

(c) The Author(s) 2021

\begin{abstract}
We previously demonstrated that village community mobilization (CM) was associated with reduced HIV incidence among adolescent girls and young women (AGYW) in South Africa. Little remains known about the mechanisms linking CM to HIV incidence. Using longitudinal data from 2292 AGYW in the HPTN 068 cohort (2011-2017), we examined whether school attendance, pro-social engagement, and hope for the future mediated the relationship between CM and HIV incidence. CM was measured at the village-level via two population-based surveys (2012 and 2014). Mediators and incident HIV infection were measured through HPTN 068 surveys and HIV testing. Mediation analyses were conducted using Mplus 8.5, adjusting for village-level clustering and covariates. Hope for the future mediated the relationship between CM and HIV incidence (indirect effect-RR 0.98, bias-corrected 95\% CI 0.96, 0.99). Pro-social engagement and school attendance did not demonstrate indirect effects. CM reduces AGYW's HIV acquisition risk, in part, by engendering hope.
\end{abstract}

Keywords Community mobilization $\cdot$ Adolescent girls and young women $\cdot$ Hope for the future $\cdot$ HIV prevention $\cdot$ South Africa

Anna M. Leddy

anna.leddy@ucsf.edu

1 Division of Prevention Science, Department of Medicine, Center for AIDS Prevention Studies, University of California, San Francisco, 550 16th St., 3rd Floor, San Francisco, CA 94158, USA

2 MRC/Wits Rural Public Health and Health Transitions Research Unit (Agincourt), School of Public Health, Faculty of Health Sciences, University of the Witwatersrand, Johannesburg, South Africa

3 Umeå Centre for Global Health Research, Division of Epidemiology and Global Health, Department of Public Health and Clinical Medicine, Umeå University, Umeå, Sweden

4 Division of Epidemiology and Biostatistics, School of Public Health, University of California Berkeley, Berkeley, CA, USA

5 Department of Epidemiology, Gillings School of Global Public Health, University of North Carolina at Chapel Hill, Chapel Hill, NC, USA

\section{Introduction}

Adolescent girls and young women (AGYW) ages 15 to 24 years in sub-Saharan Africa account for $25 \%$ of all new HIV infections globally [1]. The highest HIV incidence rates among AGYW occur in South Africa [2], indicating the urgent need to prevent new infections among this population. Central to HIV prevention efforts must be an emphasis on addressing the social environment (i.e. the socio-cultural context in which people interact), which plays a critical role in shaping HIV risk behaviors [3]. For example, social cohesion (e.g. solidarity among a group/community [4]) and social capital (e.g. trust, norms, social control, and mutual assistance available to members of a community [5, 6]) have been associated with lower rates of early sexual debut and increased condom use [7-9]. The transition from adolescence to adulthood has been identified as a period of time when the social environment may play a particularly prominent role in determining HIV risk compared to other stages of life [10-12]. During adolescence, increasing social connection to the community and engagement in prosocial activities, such as school and sports groups, have 
been associated with reduced HIV risk behaviors including condom use, the number of sexual partners, early sexual debut and substance use [13-15].

Community mobilization (CM) a process whereby community members take collective action to achieve a common goal-has emerged as a promising strategy to address aspects of the social environment that contribute to HIV risk. Our group previously developed a conceptual model and measure of CM to facilitate community engagement and identify aspects of the social environment that influence HIV outcomes [16, 17]. Defining CM as comprising seven domains (shared concerns, critical consciousness, organizational structures/links, leadership, collective action, social cohesion and social control) [16], we documented some of the first evidence of its association with reduced HIV incidence among AGYW in South Africa (Box 1) [18]. Specifically, we found that every additional standard deviation of villagelevel community mobilization was associated with a $12 \%$ lower HIV incidence among AGYW enrolled in the HPTN 068 cohort in rural South Africa [18].

Little is known about the mechanisms linking CM to HIV incidence among young female residents. Pro-social community engagement may be one mechanism. The CM process is theorized to facilitate community participation by bringing communities together in solidarity to collectively work to achieve a shared goal [19]. As described previously, pro-social engagement during adolescence, such as participating in school or sports groups, has also been associated with reduced HIV risk behaviors [13]. School attendance may be another mechanism linking CM to reduced HIV incidence. CM domains such as social control have been associated with increased educational attainment [20], and school attendance has been inversely associated with HIV incidence among AGYW in South Africa [21]. Finally, a third mechanism may be AGYW's hope for the future. The $\mathrm{CM}$ process may engender hope, as communities come together to address shared concerns and effect change. Hope for the future has also been inversely associated with HIV risk behaviors among AGYW in South Africa [22]. We examined these three hypothesized mediators of the relationship between CM and HIV incidence among AGYW in the HPTN 068 cohort in rural South Africa.

\section{Methods}

\section{Setting and Procedures}

We conducted a secondary data analysis using data from three data sources collected during our research with AGYW and their communities in the province of Mpumalanga, South Africa. The datasets include: (1) a longitudinal cohort of AGYW participating in the HPTN 068 trial, including survey and sero-prevalence data from the AGYW, and parenting and economic data reported by the heads of household; (2) two cross-sectional representative community surveys with surveys conducted in villages where the HPTN 068 cohort resided - the first survey occurred in 2012 and included 22 villages and the second was conducted in 2014 and included 26 villages; and (3) census data from the Agincourt HDSS site, where the HPTN 068 study and community surveys took place.

HPTN 068 was a phase III, randomized controlled trial of cash transfers conditional on school attendance among AGYW in the Bushbuckridge sub-district of the Mpumalanga province. The study area is within the Agincourt Health and Socio-Demographic Surveillance System (HDSS) study area, where the Medical Research Council and University of the Witwatersrand Rural Public Health and Health Transitions Research Unit conduct an annual census [23]. AGYW ages 13-20 enrolled in grades 8-11 and living in the research area were eligible to participate. All participants completed interviews and HIV testing at baseline (2011-2012), up to three annual follow-up visits (2012-2015) during the trial and an additional post-trial visit (2015-2017). Details of the HPTN 068 trial have been previously published [24, 25].

A cluster-randomized trial to test the effect of a CM intervention on harmful gender norms and HIV risk behaviors was implemented during the HPTN 068 trial in 22 villages (11 randomly selected to receive the intervention) in the Agincourt HDSS study area [26]. The CM intervention aimed to promote gender equitable norms and raise consciousness around the intersections of HIV and gender to reduce gender-based violence and improve HIV prevention behaviors and testing uptake. Intervention activities included 2-day intensive workshops led by trained community mobilizers; a range of community outreach activities; establishing and training volunteer cadres called Community Action Teams in each community; and engaging community leadership [26]. Intervention workshops were open to men and women (aged 18-35) in each intervention community and addressed seven content areas: gender, power, and health; gender and violence; alcohol; gender, HIV and AIDS; healthy relationships; human rights; and taking action for change. Mobilizers and Community Action Team members also led community outreach activities including doorto-door home visits, street soccer and soccer tournaments, mural design and discussions, and health talks. Formal leadership in each intervention community were engaged to discuss intervention themes and collaborate on activities applicable to the local context of each community. More details on the intervention content and design have been published elsewhere [26]. Two cross-sectional surveys were conducted to evaluate the 2-year CM intervention in $2012(n=1181)$, prior to the intervention, and in $2014(\mathrm{n}=1403)$, after the 
intervention [26]. Adults aged 18-35 years were randomly sampled from the census population to participate in the surveys. The $\mathrm{CM}$ survey and sampling procedures have been described in detail elsewhere [26].

\section{Measures}

The variables of interest and their data sources are depicted in Fig. 1. The outcome was HIV status, which was assessed for each HPTN 068 cohort member at every study visit and was determined by parallel HIV rapid tests [24, 25]. The exposure, village $\mathrm{CM}$, was measured at the communitylevel in both community surveys in 2012 and 2014. The $\mathrm{CM}$ measure comprised the seven domains described above. We aggregated individual responses into mean CM scores for each village, with higher scores indicating more mobilization. The development and validation of the $\mathrm{CM}$ measure has been described in detail [16].

The hypothesized mediators were AGYW pro-social engagement, hope for the future and school attendance measured for each HPTN 068 cohort member. Pro-social engagement was measured by a seven-item index that assessed whether (yes/no) participants belonged to seven different groups (e.g. sports team, student group etc.). Responses were summed to create a continuous score ranging from 0 to 7. Hope for the future was measured by a 13 -item scale developed for AGYW in the HPTN 068 cohort (Cronbach's $\alpha=0.95$ ) [22]. Example hope items include "I trust that I will be able to do everything that I want to do in my future" and "I believe the things I am doing now are preparing me for what I want in the future." Participants rated how often they agreed with the statements in the items using a 4-point Likert scale $(1=$ rarely or none of the time; $4=$ all of the time). Responses were summed to create a continuous score ranging from 1 to 52 . The hope scale was log transformed to satisfy assumptions of normality. School attendance was operationalized as a dichotomous indicator of currently in school or graduated high school vs. not attending school or dropped out.

\section{Analysis Plan}

Data from HPTN 068, the two community surveys, and the Agincourt HDSS census were merged so each HPTN visit was linked to the most recent preceding village data to ensure community (exposure) data preceded HIV outcome data, thereby preserving temporality. We restricted the dataset to participants who were HIV-negative at entry $(n=78$ with prevalent HIV infection at baseline were excluded), and to those who reside in the villages included in the community survey $(\mathrm{n}=159$ participants were excluded due to no community survey data). Finally, we excluded four participants who became HIV infected prior to having community survey data to ensure temporal ordering $(n=4)$.

We previously estimated the total effect of village $\mathrm{CM}$ on HIV incidence, demonstrating a $12 \%$ lower HIV incidence with every standard deviation increase in village mobilization score [18]. To decompose the effect of village-level CM

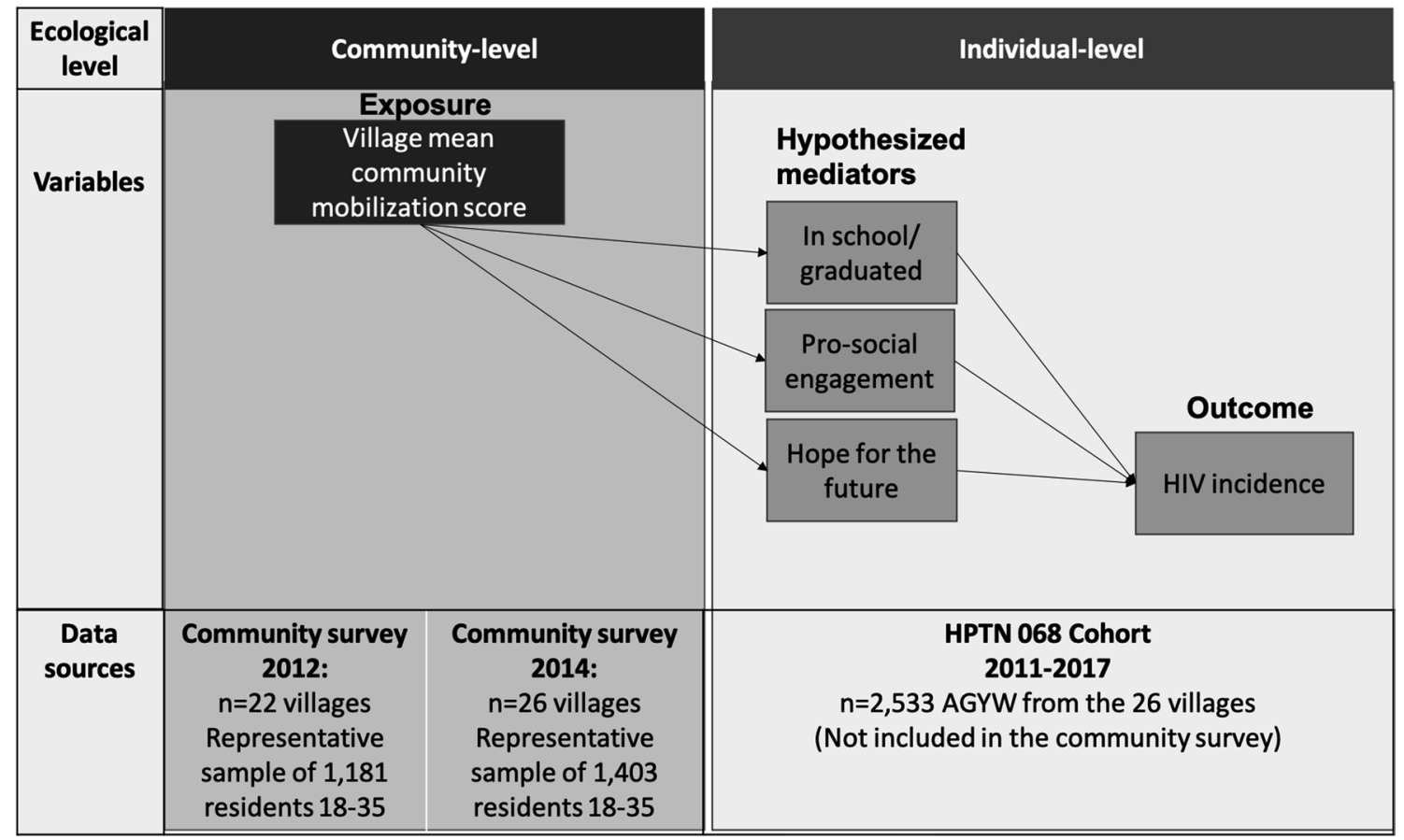

Fig. 1 Study schematic of the exposure, mediators and outcome and the contributing data sources and timelines in Agincourt, South Africa 
on HIV incidence directly versus through the hypothesized mediators, we examined the indirect effects of CM on HIV incidence using Mplus 8.5, adjusting for relevant covariates and clustering of participants within villages. The indirect effect is the association of CM with HIV incidence through the mediator(s); a significant indirect effect indicates the presence of mediation. Because indirect effects are asymmetrically distributed, we then bootstrapped the $95 \%$ confidence intervals (CI) to obtain bias corrected 95\% CIs [27]. Statistical significance of indirect effects was determined by whether the $95 \% \mathrm{CI}$ included or excluded zero. Since the value for an indirect effect is zero under the null hypothesis, if the $95 \% \mathrm{CI}$ excluded zero, the indirect effect was identified as statistically significant at $p<0.05$.

Institutional Review Board approval for HPTN 068, the community surveys, and for merging the data sources for analysis was obtained from the University of North Carolina at Chapel Hill and the University of the Witwatersrand Human Research Ethics Committee. The University of California, San Francisco approved the community surveys and protocols for merging and analyzing de-identified data. All studies were conducted in accordance with the principles outlined in the Declaration of Helsinki.

\section{Results}

The analysis included 2,292 AGYW from 26 communities. At enrollment, participants had a mean age of 15.5 years and $100 \%$ were in school (Table 1). By the end of follow-up, $88 \%$ had either graduated from high school or were still in school, and there were 194 incident infections. Community demographics did not change substantively over time.

Estimates of the mediation parameters between $\mathrm{CM}$ and HIV incidence are presented in Table 2. Hope for the future was found to mediate the relationship between CM and HIV incidence (indirect effect: RR: 0.98, bias-corrected 95\% CI $0.96,0.99, p<0.05)$. Pro-social engagement and school attendance did not demonstrate indirect effects on the relationship between CM and HIV incidence, only direct effects (Table 2).

Table 1 Baseline characteristics of HIV-negative adolescent girls and young women enrolled in HPTN $068(\mathrm{n}=2292)$ and their communities $(\mathrm{n}=26)$

\begin{tabular}{|c|c|c|}
\hline Participant characteristics & $\begin{array}{l}\text { Baseline } \\
(\mathrm{n}=2292) \\
\mathrm{n}(\%)\end{array}$ & $\begin{array}{l}\text { By the end of follow-up } \\
(\mathrm{n}=2225) \\
\mathrm{n}(\%)\end{array}$ \\
\hline Mean age at entry into $068,(\mathrm{SD})$ & $15.5(1.6)$ & - \\
\hline In school or graduated & $2229(100)$ & $1961(88.1)$ \\
\hline Mean pro-social engagement score (range $0-7),(\mathrm{SD})$ & $2.0(1.3)$ & $1.5(1.0)$ \\
\hline Mean hope for the future, logged (SD) & $3.41(0.3)$ & $2.9(0.6)$ \\
\hline Any sexual intercourse & $613(26.8)$ & $1,502(67.5)$ \\
\hline Engage in transactional sex in past 12 months $^{\mathrm{a}}$ & $72(3.1)$ & $548(36.4)$ \\
\hline Condomless sex in last three months ${ }^{\mathrm{a}}$ & $189(8.3)$ & $699(46.5)$ \\
\hline \multicolumn{3}{|l|}{ HIV status } \\
\hline HIV negative & $2292(100)$ & $2031(91.3)$ \\
\hline HIV positive & 0 & $194(8.7)$ \\
\hline Physical IPV in past 12 months & $255(10.4)$ & $950(41.32)$ \\
\hline Ever pregnant $^{\mathrm{a}}$ & $200(8.8)$ & $931(61.9)$ \\
\hline Mean number of household assets, (SD) (asked about 27 durable goods) & $14.0(0.1)$ & $15.6(0.1)$ \\
\hline Community characteristics ${ }^{\mathrm{b}}$ & $\begin{array}{l}\text { Unweighted mean (SD) } \\
2012\end{array}$ & $\begin{array}{l}\text { Unweighted mean (SD) } \\
2014\end{array}$ \\
\hline Mean years of education & $6.08(0.61)$ & $6.79(0.49)$ \\
\hline$\%$ permanent residents & $62.36(4.23)$ & $59.81(3.81)$ \\
\hline Mean SES asset score & $0.09(0.54)$ & $0.09(0.52)$ \\
\hline Community mobilization $^{\mathrm{c}}$ & $\begin{array}{l}\text { Weighted mean (SD) } \\
2012\end{array}$ & $\begin{array}{l}\text { Weighted mean (SD) } \\
2014\end{array}$ \\
\hline Total community mobilization score & $2.22(0.12)$ & $2.15(0.11)$ \\
\hline
\end{tabular}

${ }^{a}$ Among sexually active participants

${ }^{\mathrm{b}}$ Data from Agincourt Health and socio-Demographic Surveillance System census

${ }^{\mathrm{c}}$ Data from community surveys 
Table 2 Estimated direct and indirect effects of hypothesized mediators of village mean community mobilization score on HIV incidence in the HPTN 068 Cohort, Mpumalanga, South Africa, 2011-2017 $(\mathrm{n}=2292)$

\begin{tabular}{lll}
\hline Mediators $^{\mathrm{a}}$ & $\begin{array}{l}\text { Direct Effect } \\
\text { (Bias corrected 95\% CI) }\end{array}$ & $\begin{array}{l}\text { Indirect Effect } \\
\text { (Bias corrected 95\% CI) }\end{array}$ \\
\hline Girls' pro-social engagement $^{\mathrm{b}}$ & $0.84(0.73,0.98)^{*}$ & $0.99(0.98,1.01)$ \\
Girls' hope for the future $^{\text {In school/graduated high school }}$ & $0.86(0.74,1.00)$ & $0.98(0.96,0.99)^{*}$ \\
\hline
\end{tabular}

${ }^{a}$ Estimates were adjusted for household assets, HPTN intervention arm, community mobilization arm, age at baseline and community characteristics- a collated measure of three community-level variables (mean years of education, mean socio-economic status asset score, and proportion of the community who are permanent residents)

${ }^{\mathrm{b}}$ Also adjusted for in school/graduated high school

$* \mathrm{p}<0.05$

\section{Discussion}

Our group previously demonstrated that more mobilized villages were protective against HIV incidence among resident AGYW in rural South Africa (Box 1). In this manuscript, we explored hypothesized pathways linking village $\mathrm{CM}$ and HIV incidence among this population to better understand the mechanisms through which $\mathrm{CM}$ operates to prevent HIV acquisition risk and provide insight into targeted HIV prevention interventions. To our knowledge, this is the first study to find that hope for the future mediates the relationship between CM and HIV incidence. However, pro-social engagement and school attendance did not demonstrate mediation.

Hope has been theorized by other scholars to be an important mediator between the larger social environment and engagement in HIV risk behaviors [28]. Bernays et al. (2007) argue that hope is a "measurable manifestation of the ways that social and economic structures function as risk regulators for the individual" [28]. In other words, some environments may engender hope for the future, providing the opportunity for individuals to consider the long-term consequences of their behaviors, while other environments may stifle hope and constrain individuals' behaviors in such a way that gives rise to harmful behaviors and negative health outcomes [28]. Important here is individuals' internalization of the structural factors that determine health opportunity and inequality [28]. Bernays et al. argue that acknowledging the role of hope in shaping health behaviors can inform the development of HIV prevention interventions that seek to create environmental conditions that foster hope [28]. However, complex concepts such as hope can be difficult to operationalize and therefore demonstrate their effects in research. Our study provides some of the first evidence highlighting the way in which hope for the future might influence HIV outcomes. Specifically, our findings suggest that CM, which includes residents' perception of their community as cohesive and proactive, is internalized in young people. As a result, fostering mobilization is one way HIV prevention efforts can create a social environment conducive to hope and improve HIV risk reduction among AGYW.

Interestingly, we did not find that pro-social engagement or school attendance mediated the relationship between $\mathrm{CM}$ and AGYW HIV incidence, despite a theoretical basis for these pathways. It is possible that with only 194 incident infections, and 26 communities, we may have lacked the power to detect significant mediation for these hypothesized mediators [29]. It is also possible that CM has pervasive, yet diffuse impacts on a community and ensuant behaviors. While our findings suggest that CM leads to reduced AGYW HIV incidence, at least in part, through a path of hope, CM may also work through multiple additional paths (either at the community-, family-, or individual-level) that we are not measuring. For example, $\mathrm{CM}$ could be a marker

Box 1 What we have learned from past research

- Our group developed and validated a measure of community mobilization for HIV prevention in Mpumalanga Province, South Africa [16,

17]. Community mobilization comprises seven domains: shared concerns, critical consciousness, organizational structures/networks, leadership, collective action, social cohesion and social control.

- We demonstrated, through a cluster-randomized trial, that community mobilization can reduce negative gender norms among men and has the potential to create environments that support IPV prevention and reduce HIV risk behavior among young people (aged 18-35) in Mpumalanga Province, South Africa [37].

- We also documented that village-level community mobilization was associated with a $12 \%$ lower HIV incidence among adolescent girls and young women (AGYW) residing in the village [18]. 
of general community wellness, which, like other measures of 'togetherness' and 'connectedness,' can work through multiple pathways to influence health outcomes [30]. Community integration or "connectedness" has been posited to impact health outcomes by imbuing individuals with several forms of social support and resources, enforcing shared norms about health behaviors, and by facilitating a sense of attachment or belonging to ones' community [30].

Drawing on this idea, CM may also be impacting girls' HIV incidence indirectly, not through markers measured among the girls themselves, but through community members overall. The analyses conducted in this manuscript used CM measured in a representative sample in each village and the mediators and HIV incidence among AGYW residing in those villages. It is possible that $\mathrm{CM}$ may shape men's (girl's partners) behaviors, and it is men's behaviors that are also impacting AGYW incidence. South African men engage in high levels of HIV risk behaviors including concurrent partnerships, alcohol use and IPV perpetration $[31,32]$. These behaviors are, in part, driven by inequitable gender norms which value male "toughness" and power over women [33, 34]. Men who endorse such norms are more likely to engage in HIV risk behaviors and perpetrate IPV, which can increase their female partners' HIV acquisition risk [31, 35, 36]. The $\mathrm{CM}$ intervention conducted by our team was designed to address inequitable gender norms [26] and significantly increased men's endorsement of equitable gender norms in the intervention arm [37]. Thus, the protective effect of community mobilization on AGYW HIV incidence may reflect the impact of the CM intervention on men's behaviors. Indeed, AGYW enrolled in the CM intervention reported reduced rates of IPV at follow-up compared to AGYW in the control [38]. Our past research has also demonstrated that community collective efficacy, a component of community mobilization, is associated with reduced incidence of IPV among AGYW in this setting [39].

\section{Conclusion}

Our findings suggest that hope for the future is an important mediator of the impact of CM on AGYW HIV incidence. HIV prevention interventions that adopt a CM approach may alter the social environment in such a way that engenders AGYW hope for the future and enables them to engage in more HIV prevention behaviors. Future HIV prevention efforts targeted to AGYW in sub-Saharan Africa can benefit by adopting a CM approach to facilitate AGYW hope for the future. There is also a need to conduct additional research to further explore the remaining pathways linking CM to HIV incidence among AGYW in this setting, including larger sample sizes to ensure adequate power to detect differences. This research should also critically consider whether CM is impacting HIV incidence among residents through multiple diffuse pathways that may be shaping attitudes, behaviors, and norms at the community-level, including whether men's HIV-related behaviors lie on the path between CM and AGYW HIV incidence. Only by better understanding the pathways linking a mobilized community to AGYW HIV incidence can we then consider the impacts of interventions to optimize HIV risk reduction among this vulnerable population.

Acknowledgements We would like to acknowledge and thank all of the young women and their families who participated in HIV Prevention Trials Network (HPTN) 068 and made the study possible. We also thank the MRC/Wits Rural Public Health and Health Transitions Unit (Agincourt) staff who assisted with data collection for this research.

Author contributions All authors contributed to writing- review and editing. Writing- original draft preparation: AML; Conceptualization: AML, SAL, AP, JA; Methodology: SAL, TBN, JA; Formal analysis and investigation: AML, TBN, SAL; Funding acquisition: SAL, AP, KK, RT; Resources: KK, RT, SAL, AP.

Funding This research is supported by the United States National Institute of Mental Health (Grant No. R01MH110186; Pettifor). Data collection for HPTN 068 was provided by the National Institute of Allergy and Infectious Diseases (NIAID), the National Institute of Mental Health (NIMH), and the National Institute on Drug Abuse (NIDA) of the National Institutes of Health (NIH; award numbers UM1AI068619 [HPTN Leadership and Operations Center], UM1AI068617 [HPTN Statistical and Data Management Center], and UM1AI068613 [HPTN Laboratory Center]. Community survey data was supported by NIMH (R01MH087118; Pettifor and R01MH103198; Lippman/Pettifor). The MRC/Wits Rural Public Health and Health Transitions Research Unit and Agincourt Health and Socio-Demographic Surveillance System, a node of the South African Population Research Infrastructure Network (SAPRIN), is supported by the Department of Science and Innovation, the University of the Witwatersrand, and the Medical Research Council, South Africa) and formally by the Wellcome Trust, UK (Grants 058893/Z/99/A; 069683/Z/02/Z; 085477/Z/08/Z; 085477/B/08/Z). The funding institutions have not participated in the design or implementation of the study. The contents are solely the responsibility of the authors and do not necessarily represent the views of the NIH.

Data Availability The HPTN 068 data we analyzed in this paper contains sensitive health information, including HIV status and sexual behavior data, of young women in rural South Africa. In accordance with the protocol of this secondary data analysis reviewed and approved by the University of California, San Francisco Institutional Review Board, we cannot make the dataset publicly available to third party users. However, data access is managed by FHI360 and data requests can be made by contacting Erica Hamilton at EHamilton@fhi360.org.

Code Availability Not applicable.

\section{Declarations}

Conflict of interest The authors have no competing interests to disclose.

Ethical Approval Ethical approval was obtained from the University of North Carolina at Chapel Hill (16-0203), the University of the Wit- 
watersrand Human Research Ethics Committee (180305) and the University of California, San Francisco (16-19594).

Consent to Participate All participants provided written informed consent to participate.

\section{Consent for Publication Not applicable.}

Open Access This article is licensed under a Creative Commons Attribution 4.0 International License, which permits use, sharing, adaptation, distribution and reproduction in any medium or format, as long as you give appropriate credit to the original author(s) and the source, provide a link to the Creative Commons licence, and indicate if changes were made. The images or other third party material in this article are included in the article's Creative Commons licence, unless indicated otherwise in a credit line to the material. If material is not included in the article's Creative Commons licence and your intended use is not permitted by statutory regulation or exceeds the permitted use, you will need to obtain permission directly from the copyright holder. To view a copy of this licence, visit http://creativecommons.org/licenses/by/4.0/.

\section{References}

1. UNAIDS. Miles to go: closing gaps, breaking barriers, righting injustices. UNAIDS, Geneva; 2018.

2. Birdthistle I, Tanton C, Tomita A, de Graaf K, Schaffnit SB, Tanser F, et al. Recent levels and trends in HIV incidence rates among adolescent girls and young women in ten high-prevalence African countries: a systematic review and meta-analysis. Lancet Glob Health. 2019;7(11):e1521-40.

3. Berkman LF, Kawachi I. Social epidemiology. New York: Oxford University Press; 2000.

4. Kawachi I, Berkman LF. Social cohesion, social capital, and health. In: Berkman L, Kawachi I, editors. Social epidemiology. New York: Oxford University Press; 2000.

5. Moore S, Kawachi I. Twenty years of social capital and health research: a glossary. J Epidemiol Community Health. 2017;71(5):513-7.

6. Kawachi I. Commentary: social capital and health: making the connections one step at a time. Int $\mathbf{J}$ Epidemiol. 2006;35(4):989-93.

7. Lippman SA, Leslie HH, Neilands TB, Twine R, Grignon JS, MacPhail C, et al. Context matters: community social cohesion and health behaviors in two South African areas. Health Place. 2018;50:98-104

8. Campbell C, Williams B, Gilgen D. Is social capital a useful conceptual tool for exploring community level influences on HIV infection? An exploratory case study from South Africa. AIDS Care. 2002;14(1):41-54.

9. Pronyk PM, Harpham T, Morison LA, Hargreaves JR, Kim JC, Phetla G, et al. Is social capital associated with HIV risk in rural South Africa? Soc Sci Med. 2008;66(9):1999-2010.

10. Blakemore SJ, Mills KL. Is adolescence a sensitive period for sociocultural processing? Annu Rev Psychol. 2014;65:187-207.

11. Patton GC, Sawyer SM, Santelli JS, Ross DA, Afifi R, Allen NB, et al. Our future: a Lancet commission on adolescent health and wellbeing. Lancet. 2016;387(10036):2423-78.

12. National Research Council (U.S.). Panel on transitions to adulthood in developing countries. In: Llyod C, editor. Growing up global: the changing transitions to adulthood in developing countries. Washington: National Academies Press; 2005. p. 1-596.
13. Ramirez-Valles J, Zimmerman MA, Newcomb MD. Sexual risk behavior among youth: modeling the influence of prosocial activities and socioeconomic factors. J Health Soc Behav. 1998;39(3):237-53.

14. Mason MJ, Valente TW, Coatsworth JD, Mennis J, Lawrence F, Zelenak P. Place-based social network quality and correlates of substance use among urban adolescents. J Adolesc. 2010;33(3):419-27.

15. Kim J. Influence of neighbourhood collective efficacy on adolescent sexual behaviour: variation by gender and activity participation. Child Care Health Dev. 2010;36(5):646-54.

16. Lippman SA, Neilands TB, Leslie HH, Maman S, MacPhail $\mathrm{C}$, Twine $\mathrm{R}$, et al. Development, validation, and performance of a scale to measure community mobilization. Soc Sci Med. 2016;157:127-37.

17. Lippman SA, Maman S, MacPhail C, Twine R, Peacock D, Kahn K, et al. Conceptualizing community mobilization for HIV prevention: implications for HIV prevention programming in the African context. PLoS ONE. 2013;8(10):e78208.

18. Lippman SA, Leddy AM, Neilands TB, Ahern J, MacPhail C, Wagner RG, Peacock D, Twine R, Goin DE, Gómez-Olivé FX, Selin A, Tollman SM, Kahn K, Pettifor A. Village community mobilization is associated with reduced HIV incidence in young South African women participating in the HPTN 068 study cohort. J Int AIDS Soc. 2018;21:e25182.

19. Minkler M, Wallerstein NB. Improving health through community organization and community building. In: Glanz K, Rimer BK, Lewis FM, editors. Health behavior and health education: theory, research, and practice. 3rd ed. San Francisco: JosseyBass; 2002.

20. Portes A. The two meanings of social capital. Sociol Forum. 2000;15(1):1-12.

21. Stoner MCD, Pettifor A, Edwards JK, Aiello AE, Halpern CT, Julien A, et al. The effect of school attendance and school dropout on incident HIV and HSV-2 among young women in rural South Africa enrolled in HPTN 068. AIDS. 2017;31(15):2127-34.

22. Abler L, Hill L, Maman S, DeVellis R, Twine R, Kahn K, et al. Hope matters: developing and validating a measure of future expectations among young women in a high HIV prevalence setting in rural South Africa (HPTN 068). AIDS Behav. 2017;21(7):2156-66.

23. Kahn K, Collinson MA, Gomez-Olive FX, Mokoena O, Twine $\mathrm{R}$, Mee $\mathrm{P}$, et al. Profile: agincourt health and socio-demographic surveillance system. Int J Epidemiol. 2012;41(4):988-1001.

24. Pettifor A, MacPhail C, Selin A, Gomez-Olive FX, Rosenberg M, Wagner RG, et al. HPTN 068: a randomized control trial of a conditional cash transfer to reduce HIV infection in young women in South Africa-study design and baseline results. AIDS Behav. 2016;20(9):1863-82.

25. Pettifor A, MacPhail C, Hughes JP, Selin A, Wang J, GomezOlive FX, et al. The effect of a conditional cash transfer on HIV incidence in young women in rural South Africa (HPTN 068): a phase 3, randomised controlled trial. Lancet Glob Health. 2016;4(12):e978-88.

26. Pettifor A, Lippman SA, Selin AM, Peacock D, Gottert A, Maman $\mathrm{S}$, et al. A cluster randomized-controlled trial of a community mobilization intervention to change gender norms and reduce HIV risk in rural South Africa: study design and intervention. BMC Public Health. 2015;15:752.

27. Mackinnon DP, Lockwood CM, Williams J. Confidence limits for the indirect effect: distribution of the product and resampling methods. Multivariate Behav Res. 2004;39(1):99.

28. Bernays S, Rhodes T, Barnett T. Hope: a new way to look at the HIV epidemic. AIDS. 2007;21(Suppl 5):S5-11.

29. Rudolph KE, Goin DE, Stuart EA. The peril of power: a tutorial on using simulation to better understand when and 
how we can estimate mediating effects. Am J Epidemiol. 2020;189(12):1559-67.

30. Berkman LF, Glass T. Social integration, social networks, social support, and health. In: Berkman LF, Kawachi I, editors. Social epidemiology. New York: Oxford University Press; 2000.

31. Gottert A, Barrington C, McNaughton-Reyes HL, Maman S, MacPhail C, Lippman SA, et al. Gender norms, gender role conflict/stress and HIV risk behaviors among men in Mpumalanga, South Africa. AIDS Behav. 2018;22(6):1858-69.

32. Okafor CN, Christodoulou J, Bantjes J, Qondela T, Stewart J, Shoptaw S, et al. Understanding HIV risk behaviors among young men in South Africa: a syndemic approach. AIDS Behav. 2018;22(12):3962-70.

33. Jewkes R, Morrell R. Gender and sexuality: emerging perspectives from the heterosexual epidemic in South Africa and implications for HIV risk and prevention. J Int AIDS Soc. 2010;13:6.

34. Connell RW, Messerschmidt JW. Hegemonic masculinity rethinking the concept. Gend Soc. 2005;19(6):829-59.

35. Li Y, Marshall CM, Rees HC, Nunez A, Ezeanolue EE, Ehiri JE. Intimate partner violence and HIV infection among women: a systematic review and meta-analysis. J Int AIDS Soc. 2014;17:18845.

36. Shannon K, Leiter K, Phaladze N, Hlanze Z, Tsai AC, Heisler $\mathrm{M}$, et al. Gender inequity norms are associated with increased male-perpetrated rape and sexual risks for HIV infection in Botswana and Swaziland. PLoS ONE. 2012;7(1):e28739.

37. Pettifor A, Lippman SA, Gottert A, Suchindran CM, Selin A, Peacock D, et al. Community mobilization to modify harmful gender norms and reduce HIV risk: results from a community cluster randomized trial in South Africa. J Int AIDS Soc. 2018;21(7):e25134.

38. Gottert A, Pulerwitz J, Haberland N, Mathebula R, Rebombo D, Spielman K, et al. Gaining traction: Promising shifts in gender norms and intimate partner violence in the context of a community-based HIV prevention trial in South Africa. PLoS ONE. 2020;15(8): 0237084.

39. Leddy AM, Lippman SA, Neilands TB, Twine R, Ahern J, GomezOlive FX, et al. Community collective efficacy is associated with reduced physical intimate partner violence (IPV) incidence in the rural province of Mpumalanga, South Africa: findings from HPTN 068. J Epidemiol Commun Health. 2019;73(2):176-81.

Publisher's Note Springer Nature remains neutral with regard to jurisdictional claims in published maps and institutional affiliations. 